\title{
Rapid Solidification Characteristics of Highly Undercooled Liquid Ni-Cu-Mo-Ge Quaternary Alloy under Electromagnetic Levitation Condition
}

\author{
Jian Chang, Haipeng Wang, Bingbo Wei* \\ Department of Applied Physics, Northwestern Polytechnical University, \\ Xi'an 710072 , China
}

\begin{abstract}
The dendritic growth characteristics of undercooled

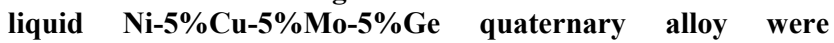
investigated by electromagnetic levitation method. The measured dendritic growth velocity of $\alpha-\mathrm{Ni}$ phase increases with undercooling according to a power law relation, which attains a value of $28 \mathrm{~m} / \mathrm{s}$ at the maximum undercooling of 321 $\mathrm{K}\left(0.19 T_{\mathrm{L}}\right)$. The microstructure morphology appears as coarse dendrites at small undercoolings, while it is refined into equiaxed grains at substantial undercoolings. Furthermore, all the solute elements $\mathrm{Cu}$, Mo and Ge exhibit a significant solute trapping effect during rapid dendritic growth.
\end{abstract}

Keywords-dendritic growth; high undercooling; solute trapping.

\section{INTRODUCTION}

Rapid dendritic growth within highly undercooled liquid alloy has aroused great research interest, which significantly influences the microstructures, solute distribution and application performances of alloys[1-5]. The dendritic growth velocity is an important and fundamental parameter for revealing nonequilibrium solidification process and controlling the alloy properties[6-10]. High dendritic growth velocity results in the remarkable solute trapping and almost segregationless solidification according to rapid solidification studies of binary alloys[11, 12]. However, the investigations about dendritic growth of alloys mainly focused on pure metals and binary alloys[13-17]. Experimental studies of rapid solidification for multicomponent alloys are scarce and the mechanism of interactions between different solutes is still unclear. It is desirable to perform the systematic study about the rapid solidification of multicomponent alloys.

Based on the previous study of ternary $\mathrm{Ni}-5 \% \mathrm{Cu}-5 \% \mathrm{Mo}$ alloy[18], semiconductor element $\mathrm{Ge}$ is chosen to form a $\mathrm{Ni}-5 \% \mathrm{Cu}-5 \% \mathrm{Mo}-5 \% \mathrm{Ge}$ quaternary alloy in order to explore the dendrites growth mechanism and different segregation profiles of three solute elements.

\section{EXPERIMENTAL PROCEDURE}

$\mathrm{Ni}-5 \% \mathrm{Cu}-5 \% \mathrm{Mo}-5 \% \mathrm{Ge}$ quaternary alloy samples were prepared from $99.99 \% \mathrm{Ni}, 99.999 \% \mathrm{Cu}, 99.97 \% \mathrm{Mo}$ and 99.9999\% Ge by arc melting under an Ar atmosphere and the mass of each melted sample is about $0.8 \mathrm{~g}$. All rapid solidification experiments were performed in a vacuum chamber evacuated to a pressure of $10^{-5} \mathrm{~Pa}$, then backfilled with a mixture of $\mathrm{He}$ and Ar gases in the volume rate of $1: 1$. The alloy sample was containerlessly melted in the center of the electromagnetic levitation coil, as shown in Figure 1. Its temperature was monitored by a Raytek Marathon MR1S infrared pyrometer. By cooling with $\mathrm{He}$ gas which was refrigerated by liquid nitrogen, the liquid alloy sample achieved substantial undercooling. The dendritic growth velocity was determined by a photodiode device.

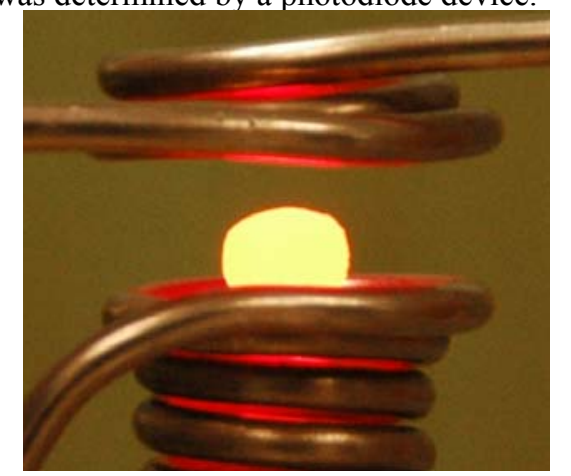

Figure 1. Electromagnetic levitation of an alloy sample

After rapid solidification experiments, the samples were sectioned, polished and etched with chromotropic acid. The phase constitution, microstructure and solute distribution were analyzed by a Rigaku D/max $2500 \mathrm{x}$-ray diffractometer, a Zeiss Axiovert 200 Mat optical microscope and an Oxford INCA Energy 300 energy-dispersive spectrometer. The equilibrium phase transformation characteristics were determined by a Netzsch 404C differential scanning calorimeter. 


\section{RESULTS AND DISCUSSION}
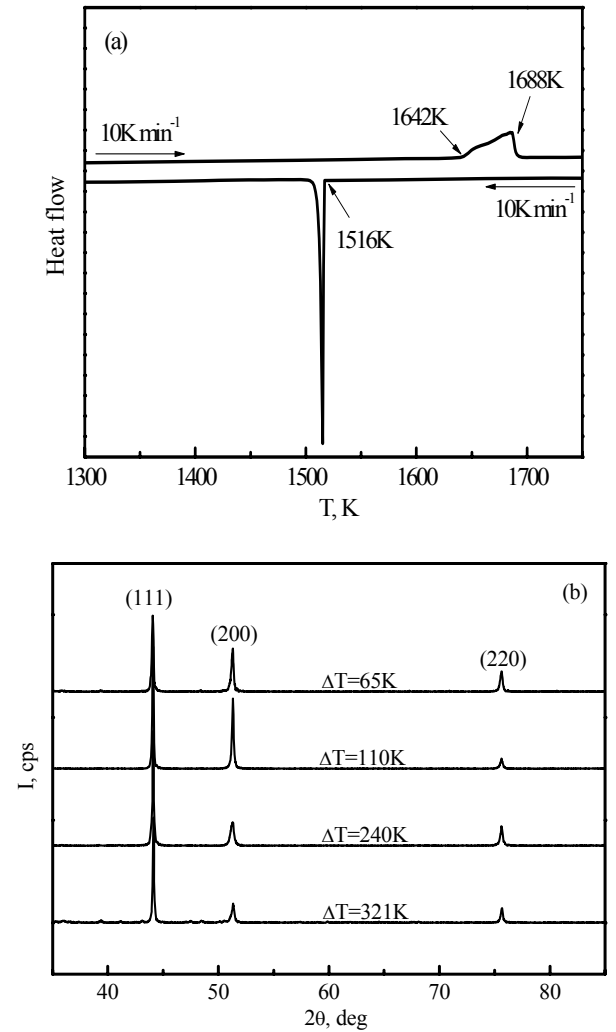

Figure 2. DSC curve (a) and X-ray diffraction patterns (b) of Ni-5\%Cu$5 \% \mathrm{Mo}-5 \% \mathrm{Ge}$ alloy with different undercoolings

Thermal analysis and X-ray diffraction analysis were carried out to determine the phase constitution of $\mathrm{Ni}-5 \% \mathrm{Cu}$ $5 \% \mathrm{Mo}-5 \% \mathrm{Ge}$ alloy. The DSC curve of this alloy is presented in Figure 2(a). It illustrates that there is only one peak during melting or solidification process, which indicates that one phase transformation occurs. Furthermore, the liquidus temperature is determined to be $1688 \mathrm{~K}$. The undercooling obtained under $10 \mathrm{~K} / \mathrm{min}$ cooling velocity condition is $172 \mathrm{~K}$, it is slightly smaller than $202 \mathrm{~K}$ which is obtained in the thermal analysis of $\mathrm{Ni}-5 \% \mathrm{Cu}-5 \% \mathrm{Mo}$ alloy under the same condition[18]. Figure 2(b) shows the diffraction patterns of four samples prepared at 65, 110, 240 and $321 \mathrm{~K}$ undercooling. All four diffraction patterns are quite similar to that of pure $\mathrm{Ni}$ even when the undercooling reaches $0.19 \mathrm{~T}_{\mathrm{L}}$. A tiny offset of the diffraction peaks compared with pure $\mathrm{Ni}$ is detected because of the extended solubility of $\mathrm{Cu}$, Mo and Ge elements. Therefore, it can be confirmed that no new metastable phase exists and the samples are composed of a single $\alpha$-Ni solid solution phase.

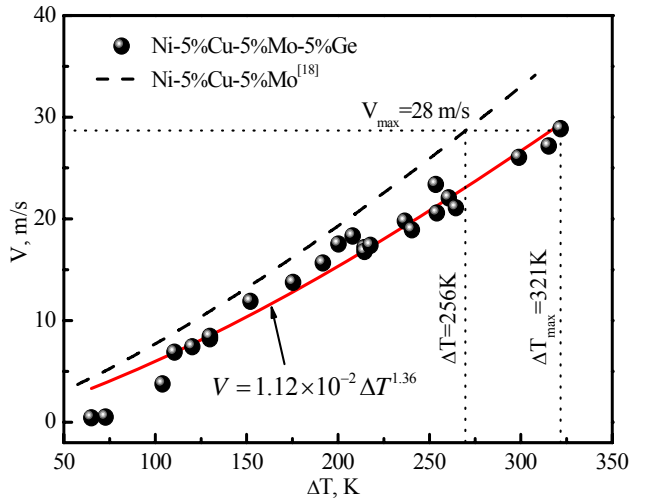

Figure 3. Dendrite growth velocity of $\alpha-\mathrm{Ni}$ phase as a function of undercooling

Figure 3 presents the dendritic growth velocity of $\alpha-\mathrm{Ni}$ phase measured at different undercoolings. It shows a power relation to undercooling $\Delta T_{\mathrm{L}}$, which can be described as:

$$
V=1.12 \times 10^{-2} \Delta T^{1.36} \mathrm{~m} / \mathrm{s} .
$$

At the maximum undercooling of $321 \mathrm{~K}\left(0.19 \mathrm{~T}_{\mathrm{L}}\right)$, the growth velocity attains $28 \mathrm{~m} / \mathrm{s}$. Whereas the growth velocity of $\alpha-\mathrm{Ni}$ phase in $\mathrm{Ni}-5 \% \mathrm{Cu}-5 \% \mathrm{Mo}$ alloy attain the value of $28 \mathrm{~m} / \mathrm{s}$ at the undercooling $256 \mathrm{~K}$. Therefore, the introduction of $\mathrm{Ge}$ remarkably decreases the dendritic growth velocity.
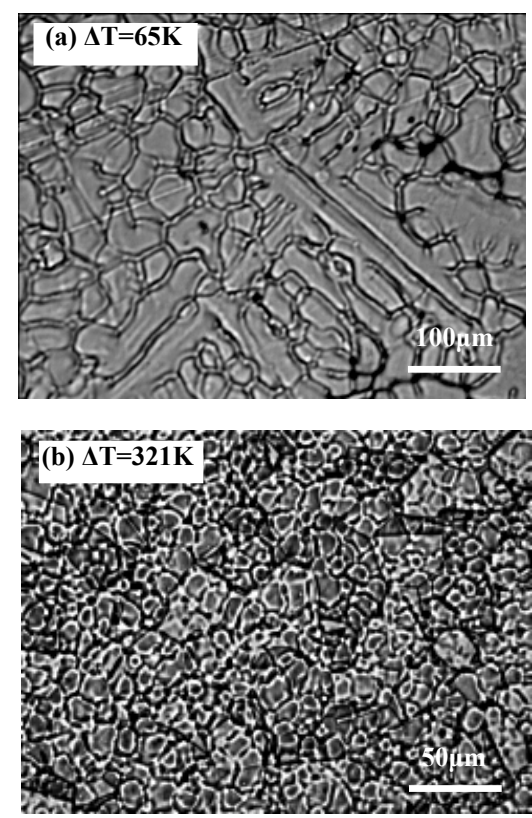
Figure 4. Microstructure characteristics of undercooled Ni-5\% Cu- $5 \% \mathrm{Mo}-$ $5 \%$ Ge alloy at (a) $65 \mathrm{~K}$ and (b) $321 \mathrm{~K}$ undercoolings.

The typical microstructures of $\mathrm{Ni}-5 \% \mathrm{Cu}-5 \% \mathrm{Mo}-5 \% \mathrm{Ge}$ alloy are illustrated in Fig. 4. Figure 4(a) displays that the microstructure is characterized by coarse dendrites when the samples are solidified at a low undercooling of $65 \mathrm{~K}$. At high undercoolings, the microstructural morphology transforms from dendrites to equiaxed grains with a grain refinement effect, as shown in Figure 4(b).
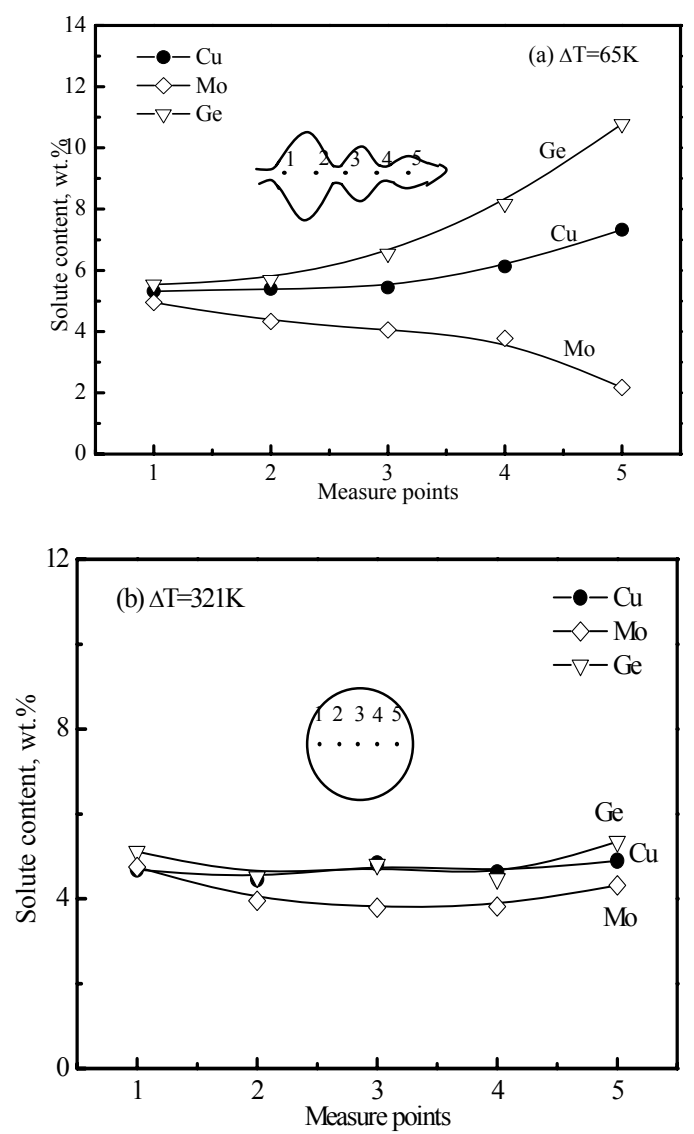

Figure 5. Solute distribution in the samples undercooled by (a) $65 \mathrm{~K}$ and (b) $321 \mathrm{~K}$

The solute distributions of $\mathrm{Cu}$, Mo and Ge inside the $\alpha$ $\mathrm{Ni}$ solid solution phase were investigated by EDS analysis, as shown in Figure 5. In the center of primary dendrite trunk obtained at low undercooling of $65 \mathrm{~K}$, the solute concentration of $\mathrm{Ge}$ is larger than that of $\mathrm{Cu}$. Both of them are larger than the original composition and increase along the growth direction of the primary dendrite trunk. Meanwhile, the solute concentration of Mo is smaller than the original composition and decrease along the primary dendrite trunk. The solute distributions of $\mathrm{Cu}$ and Mo in this quaternary alloy are opposite with those in $\mathrm{Ni}-5 \% \mathrm{Cu}-5 \% \mathrm{Mo}$ alloy in which the solute concentration of $\mathrm{Cu}$ is smaller than that of Mo. This is mainly due to the addition of Ge which has different interactions with $\mathrm{Cu}$ and Mo.
With the rise of undercooling, the solute trapping effect becomes more remarkable. Figure 5(b) reveals that the concentrations of $\mathrm{Cu}, \mathrm{Mo}$ and $\mathrm{Ge}$ are close to the original composition at the maximum undercooling of $321 \mathrm{~K}$. All solute distributions are quite uniform and microsegregation can be hardly detected in the equiaxed grains.

\section{CONCLUSIONS}

The high undercooling state of liquid $\mathrm{Ni}-5 \% \mathrm{Cu}-5 \% \mathrm{Mo}-$ $5 \% \mathrm{Ge}$ alloy was achieved by electromagnetic levitation method. The maximum undercooling in the experiments was $321 \mathrm{~K}\left(0.19 \mathrm{~T}_{\mathrm{L}}\right)$. At such a substantial undercooling, no new metastable phase exists and the samples are composed of a single $\alpha$-Ni solid solution phase. Its dendritic growth velocity increases with undercooling by following a power law relation. The measured maximum growth velocity is 28 $\mathrm{m} / \mathrm{s}$. As compared with $\mathrm{Ni}-5 \% \mathrm{Cu}-5 \% \mathrm{Mo}$ alloy, the introduction of solute Ge remarkably decreases the dendritic growth velocity of $\alpha$-Ni phase. The solidified microstructure is mainly characterized by a morphological transition from coarse dendrites to equiaxed grains with the rise of undercooling. The rapid dendritic growth results in remarkable solute trapping effect for all the three solute elements and segregationless solidification was almost achieved.

\section{ACKNOWLEDGEMENTS}

The authors are grateful to Drs. K. Zhou, W. L. Wang, and D. L. Geng for their help during the experiment and for valuable discussions. This research was supported by National Science Foundation of China under Grants No. 51271150.

\section{REFERENCES}

[1] Woodcock, T. G., Shuleshova, O., Gehrmann, B. \& Löser, W., Microstructural transitions in commercial Fe-Ni-Based soft-magnetic alloys quenched from undercooled liquid droplets., Metall. Mater. Trans. A, 39(12), pp. 2906-2913, (2008).

[2] Wang Q., Ma M. Z., Jing Q., Li G., Qi L., Zhang X. Y., Wang W. K. \& Liu R. P., Undercooling and unidirectional solidification of $\mathrm{CuNi}$ alloy melts., Chin. Phys. Lett., 25(10), pp. 3808-3810, (2008).

[3] Chan, W.-L., Averback, R. S., Cahill, D. G. \& Ashkenazy, Y., Solidification velocities in deeply undercooled silver., Phys. Rev. Lett., 102(9), pp. 095701-1 4, (2009).

[4] Lü, Y. J., Crystal growth velocity in deeply undercooled Ni-Si alloys., Philos. Mag. Lett., 92(2), pp. 56-66, (2011).

[5] Kim, Y. W. Martensitic transformation behaviors of rapidly solidified Ti-Ni-Si alloys., Intermetallics, 38, pp. 4-8, (2013).

[6] Trivedi, R., Lipton, J. \& Kurz, W., Effect of growth rate dependent partition coefficient on the dendritic growth in undercooled melts, Acta Metall., 35(4), pp. 965-970, (1987).

[7] Lipton, J., Kurz, W. \& Trivedi, R., Rapid dendrite growth in undercooled alloys, Acta Metall., 35(4), pp. 957-964, (1987).

[8] Walder, S., Dendritic growth rate in undercooled dilute Ti-Ni melts., Mater. Sci. Eng. A, 229(1-2), pp. 156-162, (1997). 
[9] Castle, E. G., Mullis, A. M. \& Cochrane, R. F., Evidence for an extensive undercooling-mediated transition in growth orientation and novel dendritic seaweed microstructures in $\mathrm{Cu}-8.9 \mathrm{wt} . \% \mathrm{Ni}$., Acta Mater. 66, pp. 378-387, (2014).

[10] Sun, D. Y., Mendelev, M. I., Becker, C. A., Kudin, K., Haxhimali, Tomorr, Asta, M., Hoyt, J. J., Karma, A. \& Srolovitz, D. J., Crystalmelt interfacial free energies in hcp metals: a molecular dynamics study of Mg., Phys. Rev. B, 73(2), pp. 024116-1 12, (2006).

[11] Wang, H. P., Yao, W. J. \& Wei, B., Remarkable solute trapping within rapidly growing dendrites., Appl. Phys. Lett., 89(20), pp. 201905-1 3, (2006).

[12] Galenko, P., Solute trapping and diffusionless solidification in a binary system., Phys. Rev. E, 76(3), pp. 031606-1 9, (2007).

[13] Battersby, S. E., Cochrane, R. F. \& Mullis, A. M., Highly undercooled germanium: Growth velocity measurements and micro structural analysis., Mater. Sci. Eng. A, 226-228, pp. 443-447, (1997).
[14] Drewes, K., Schaefers, K., Roesner-Kuhn, M. \& Frohberg, M. G., Measurements of dendritic growth and recalescence rates in undercooled melts of cobalt., Mater. Sci. Eng. A, 241(1-2), pp. 99-103, (1998).

[15] Algoso, P. R., Hofmeister, W. H. \& Bayuzick, R. J., Solidification velocity of undercooled Ni-Cu alloys., Acta Mater., 51(14), pp. 43074318, (2003).

[16] Yang, Y., Humadi, H., Buta, D., Laird, B. B., Sun, D. Y., Hoyt, J. J. \& Asta, M., Atomistic simulations of nonequilibrium crystal-growth kinetics from alloy melts., Phys. Rev. Lett., 107(2), pp. 025505-1 4, (2011)

[17] Mullis, A. M., Prediction of the operating point of dendrites growing under coupled thermosolutal control at high growth velocity., Phys. Rev. E, 83(6), pp. 061601-1 9, (2011).

[18] Chang, J., Wang, H. P., Zhou, K. \& Wei, B., Rapid dendritic growth and solute trapping within undercooled ternary $\mathrm{Ni}-5 \% \mathrm{Cu}-5 \% \mathrm{Mo}$ alloy., Appl. Phys. A, 109(1), pp. 139-143, (2012). 